\title{
МИКРОСКОПИЧЕСКИЙ АНАЛИЗ ПОВЕРХНОСТИ ГЕТЕРОГЕННЫХ МЕМБРАН С РАЗНОЙ СТЕПЕНЬЮ ДИСПЕРСНОСТИ ИОНООБМЕННИКА ПОСЛЕ ТЕМПЕРАТУРНОГО ВОЗДЕЙСТВИЯ
}

\author{
(ㄷ 2017 Э. М. Акберова, Е. Ю. Кожухова, А. М. Яцев, В. И. Васильева \\ Воронежский государственный университет, Университетская пл., 1, 394018 Воронеж, Россия \\ e-mail: elmara_09@inbox.ru
}

Поступила в редакцию 30.03.2017 г.

\begin{abstract}
Аннотация. Микроскопическими методами анализа визуализированы различия в микроструктуре поверхности набухших образцов экспериментальных сульфокатионообменных мембран Ralex CM Pes (Чехия) с разным временем измельчения ионообменника. Выявлено уменьшение размеров и сближение зон проводящей фазы на поверхности мембран, содержащих ионообменник, подвергнутый большему времени измельчения. Методом РЭМ показано, что в результате длительного воздействия повышенных температур происходит увеличение макропористости, появление новых дефектов структуры, уменьшение доли ионообменной фазы на поверхности мембран.
\end{abstract}

Ключевые слова: гетерогенная сульфокатионообменная мембрана, неоднородность поверхности, температурное воздействие.

\section{ВВЕДЕНИЕ}

В настоящее время одно из направлений, по которому идет совершенствование электромембранных методов разделения и выделения веществ,разработка новых мембран с оптимизированной морфологией поверхности. Использование таких мембран в процессе электродиализа для обессоливания и деионизации природных вод и технологических растворов создает предпосылки для существенного повышения эффективности этих процессов в сверхпредельных токовых режимах за счет развития электроконвекции.

Известно, что свойства поверхности мембран (электрическая и геометрическая неоднородность, степень гидрофобности и т.д.) влияют на интенсивность электроосмотической конвекции в растворе на границе с ионообменной мембраной [1-9]. Неоднородное распределение пространственного заряда на границе мембрана/раствор, возникающее вследствие чередования участков проводящего и непроводящего материала на поверхности (электрическая неоднородность), способствует возникновению электроконвективной нестабильности [2]. Увеличение доли проводящей поверхности экспериментальной сильноосновной мембраны на основе анионообменника с меньшей степенью сшивки по сравнению с промышленно выпускаемой мембраной в 1.4 раза привело к более чем двукратно- му росту предельного и сверхпредельного тока по сравнению с исходной мембраной [10]. Получение поверхностно модифицированных мембран с большей проводящей поверхностью за счет воздействия повышенных температур [11] способствует переходу в нестабильный режим электроконвекции при гораздо меньших значениях скачка потенциала. В ряде работ $[12,13]$ сопоставление ВАХ гомогенных и гетерогенных мембран выявило, что гомогенизация поверхности приводит к росту предельной диффузионной плотности тока и сокращению участка плато вольтамперной кривой. С другой стороны, из работ $[3,5,14-16]$ известно, что более выраженная геометрическая неоднородность поверхности (микрорельеф) мембран облегчает возникновение и развитие электроконвективной нестабильности вследствие роста тангенциальной составляющей электрической силы.

Целью настоящей работы являлся сравнительный анализ микроструктуры поверхности экспериментальных образцов гетерогенных мембран с разной степенью дисперсности ионообменника после температурного воздействия.

\section{ЭКСПЕРИМЕНТАЛЬНАЯ ЧАСТЬ}

В работе исследовались экспериментальные образцы гетерогенных катионообменных мембран CM Pes («MEGA a.s.», Чехия). Мембрана 
CM Pеs является композитом сульфокатионообменника $(58 \%)$ с полиэтиленом и армирующей тканью полиэстер [17]. Мембраны были получены вальцеванием гомогенизированной смеси измельченного ионообменника с различной степенью дисперсности с полиэтиленом. Степень дисперсности сульфокатионообменника варьировалась путем использования разного времени его измельчения. Исследуемые образцы мембран вначале подвергали солевой предподготовке, затем термостатировали при температуре $100{ }^{\circ} \mathrm{C}$ в дистиллированной воде в течение 50 ч.

Исследования поверхности мембран проводили методом растровой электронной микроскопии (РЭМ) с применением микроскопа марки JSM-6380 LV (Япония) при кратности увеличении 500. Регулируемое давление в камере с исследуемым образцом позволило исследовать в низковакуумном режиме мембраны в рабочем (набухшем) состоянии $[18,19]$. Количественная оценка доли ионообменного материала $S$ и порового состава $P$ на поверхности мембран проводилась с помощью авторского программного комплекса [20]. Долю ионообменника определяли по формуле $S=\left(\Sigma S_{i} / S\right) \cdot 100 \%$, где $\Sigma S_{i}-$ суммарная площадь ионообменных участков, $S$ - площадь сканируемого участка. Под радиусом ионообменного участка $R$ понимали эффективный радиус моделируемого программой участка круглой формы по площади эквивалентного реальной площади ионообменника произвольной формы. При вычислении среднего радиуса ионообменника брали средневзвешенное значение [18], учитывающее различную долю участков с отличающимися размерами. Долю $P$ и средневзвешенное значение радиуса пор $\bar{r}$ на поверхности мембран рассчитывали аналогичным образом. За степень дисперсности $D$ ио- нообменных частиц принимали величину, обратную их диаметру [21].

Микрорельеф поверхности мембран исследовали методом атомно-силовой микроскопии (АСМ) на микроскопе SolverP47 Pro (Россия, Зеленоград) в полуконтактном режиме на сухих образцах [22]. Сканирование осуществляли кантилевером типа NSG20 длиной $90 \pm 5$ мкм с резонансной частотой 260-630 кГц и радиусом кривизны острия зонда 10 нм. Площадь сканирования составляла $10 \times 10$ мкм. Эксперименты проводили на воздухе при температуре $25 \pm 1{ }^{\circ} \mathrm{C}$. Обработка полученных АСМ-изображений осуществлялась с помощью программного обеспечения ACM Solver P47 Pro Nova RC1. Проводился анализ амплитудных среднестатистических параметров шероховатости поверхности в соответствии с международными стандартами ISO 4287/1 и ANSI B. 46.1: $R_{y}$ - размах высот; $R_{a}$ - средняя арифметическая шероховатость. Полученные гистограммы распределения высот характеризовали рельеф поверхности всего образца мембраны.

\section{РЕЗУЛЬТАТЫ И ИХ ОБСУЖДЕНИЕ}

Электрическая неоднородность поверхности мембран характеризуется долей и размерами проводящих участков (частицы ионообменника и поры около них) поверхности. Из анализа микрофотографий набухших образцов мембран (рис. 1) установлено, что доля ионообменника для гетерогенных мембран СM Pes составляет 15-17\% (табл. 1).

Сравнительный анализ распределения ионообменных участков по радиусам показывает, что максимум на кривой распределения для кондиционированных образцов мембран находился в области 1-2 мкм (рис. 2). С ростом времени измельчения

Таблица 1. Характеристики поверхности образцов гетерогенных мембран CM Pes после кондиционирования и нагревания в воде при $100{ }^{\circ} \mathrm{C}$ в течение 50 ч

[Table 1. Surface characteristics of CM Pes heterogeneous membranes samples after conditioning and heating in water at $100{ }^{\circ} \mathrm{C}$ for $\left.50 \mathrm{~h}\right]$

\begin{tabular}{|c|c|c|c|c|c|c|c|}
\hline $\begin{array}{c}\text { Время } \\
\text { измельче- } \\
\text { ния, мин } \\
\text { [Milling } \\
\text { time, min] }\end{array}$ & $\begin{array}{c}\text { Воздействие } \\
{[\text { Treatment] }}\end{array}$ & $S, \%$ & $\begin{array}{c}\bar{R}, \text { мкм } \\
{[\bar{R}, \mu \mathrm{M}]}\end{array}$ & $\begin{array}{c}R_{\min }-R_{\max }, \text { мкм } \\
{\left[R_{\min }-R_{\max }, \mu \mathrm{M}\right]}\end{array}$ & $P, \%$ & $\begin{array}{c}\bar{r}, \text { мкм } \\
{[\bar{r}, \mu \mathrm{M}]}\end{array}$ & $\begin{array}{c}r_{\min }-r_{\max }, \text { мкм } \\
{\left[r_{\min }-r_{\max }, \mu \mathrm{M}\right]}\end{array}$ \\
\hline \multirow{2}{*}{5} & конд. [cond.] & $16.6 \pm 0.7$ & $1.85 \pm 0.07$ & $0.6-15.0$ & $2.7 \pm 0.2$ & $1.55 \pm 0.03$ & $0.4-7.0$ \\
\cline { 2 - 9 } & нагрев. [heat.] & $8.8 \pm 0.4$ & $2.42 \pm 0.07$ & $0.7-12.0$ & $6.8 \pm 0.8$ & $2.0 \pm 0.2$ & $0.5-8.0$ \\
\hline \multirow{2}{*}{80} & конд. [cond.] & $15 \pm 1$ & $1.52 \pm 0.03$ & $0.4-9.0$ & $1.81 \pm 0.05$ & $1.27 \pm 0.04$ & $0.3-5.0$ \\
\cline { 2 - 8 } & нагрев. [heat.] & $11.5 \pm 0.2$ & $2.0 \pm 0.1$ & $0.6-11.0$ & $9.8 \pm 0.6$ & $1.56 \pm 0.04$ & $0.3-8.0$ \\
\hline
\end{tabular}




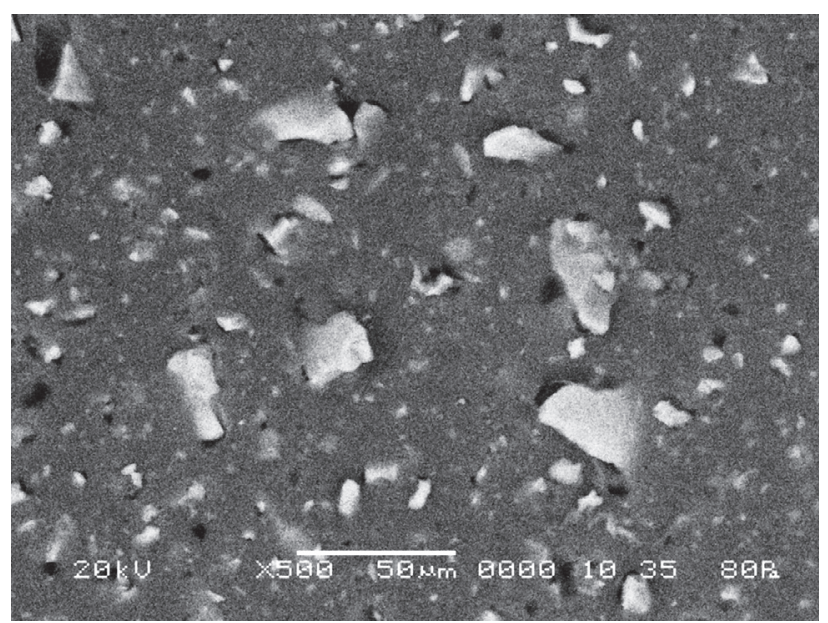

$a$

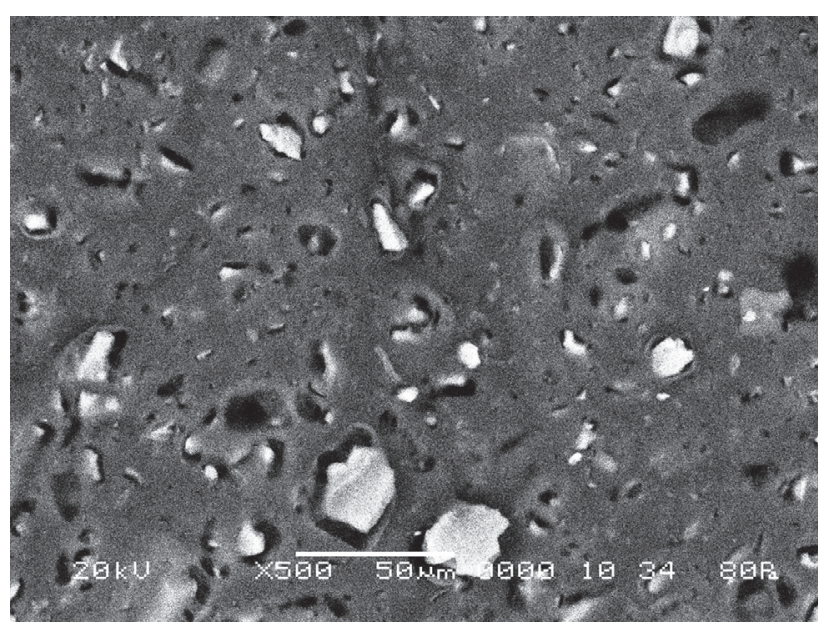

c

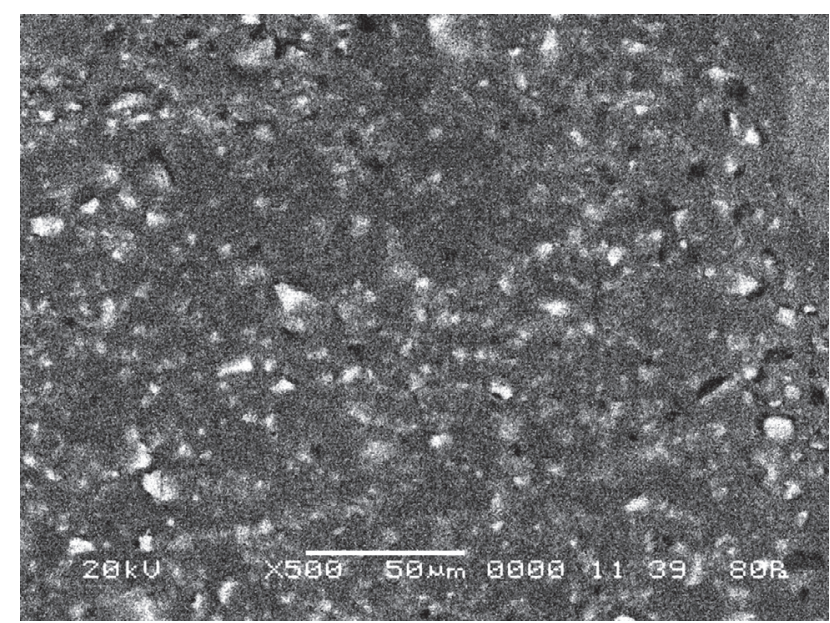

$b$

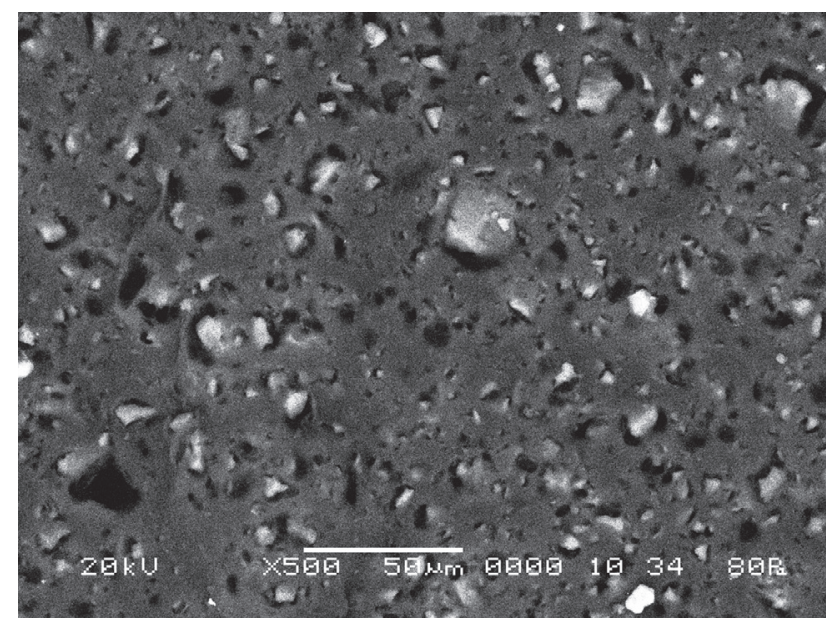

$d$

Рис. 1. РЭМ-изображения поверхности набухших образцов сульфокатионообменной мембраны СМ Реs при увеличении 500 после кондиционирования $(a, b)$ и нагревания в воде при $100{ }^{\circ} \mathrm{C}$ в течение 50 ч $(c, d)$. Время измельчения ионообменника: 5 мин $(a, c)$ и 80 мин $(b, d)$

[Fig. 1. SEM images of the surface of the CM Pes sulfocation exchange membrane swollen samples at an magnification of 500 after conditioning $(a, b)$ and heating in water at $100^{\circ} \mathrm{C}$ for $50 \mathrm{~h}(c, d)$. Ion exchanger milling time: $5 \mathrm{~min}(a, c)$ and $80 \min (b, d)]$

ионообменных частиц визуализируется увеличение их общего количества и значительное возрастание доли ионообменника с радиусом менее 0.7 мкм. Увеличение продолжительности измельчения ионообменных частиц соответствует изменению их степени дисперсности: для образцов мембран с измельчением ионообменника в течение 5 и 80 мин разброс величин степени дисперсности составляет $(3-80) \cdot 10^{4} \mathrm{M}^{-1}$ и $(6-120) \cdot 10^{4} \mathrm{M}^{-1}$ соответственно. С увеличением степени дисперсности ионообменных частиц на поверхности набухших образцов мембран СM Pes значение их средневзвешенного радиуса уменьшается на 20\% и составляет $1.52 \pm 0.03$ мкм для мембран с максимальным временем измельчения ионообменников. Согласно оценкам, прове- денным в работе [6], значение средневзвешенного радиуса для серийно выпускаемой компанией «MEGA a.s.» сульфокатионообменной мембраны Ralex CM Pes составляет $\bar{R}=1.88$ мкм.

Уменьшение размеров ионопроводящих участков на поверхности экспериментальных мембран CM Pes c ростом времени измельчения сопровождается сближением зон проводящей поверхности: эффективное расстояние между ионообменниками уменьшается более чем вдвое и составляет 11.45 и 5.49 мкм для времени измельчения 5 и 80 мин соответственно.

Микрофотографии поверхности мембран в набухшем состоянии позволяют оценить размеры переходной области между проводящими и непрово- 


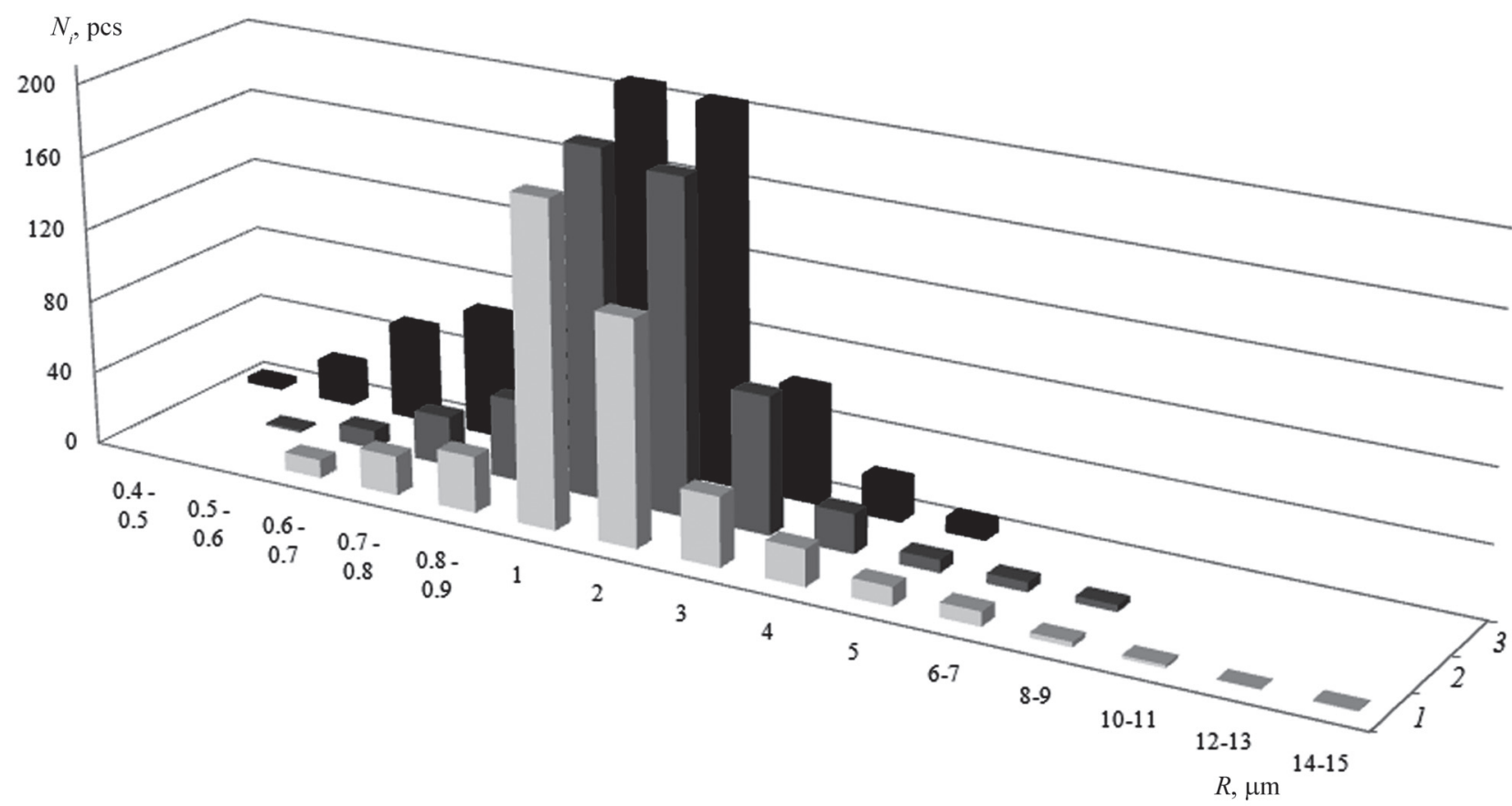

Рис. 2. Распределение участков ионообменника по радиусам на поверхности набухших образцов ионообменных мембран СМ Реs со временем измельчения ионообменника 5 (1), 40 (2) и 80 (3) мин

[Fig. 2. Distribution of the ion exchange areas over radii on the surface of the swollen samples of CM Pes ion exchange membranes with an ion exchanger milling time of 5 (1), 40 (2) and 80 (3) min]

дящими участками и размеры дефектов структуры. Установлена существенная разница величин общей поверхностной пористости мембран CM Pes с разной степенью дисперсности ионообменника. С ростом продолжительности измельчения ионообменных частиц от 5 до 80 мин макропористость на поверхности кондиционированных мембран в набухшем состоянии уменьшается с 2.7 до $1.8 \%$, при этом средневзвешенные величины радиусов пор составляют $1.55 \pm 0.03$ и $1.27 \pm 0.04$ мкм соответственно. Увеличение степени дисперсности ионообменника является одной из основных причин уменьшения радиуса и площади макропор на поверхности [19].

Сравнение микрорельефа поверхности экспериментальных гетерогенных катионообменных мембран CM Pes в сухом состоянии представлено на рис. 3. Мембрана с большей степенью дисперсности ионообменника характеризовалась более гладкой в микрометрическом масштабе поверхностью: размах высот $R_{\mathrm{y}}$ и средняя арифметическая шероховатость $R_{\mathrm{a}}$ составляли 286 и 12 нм соответственно. Изображение поверхности мембраны, содержащей ионообменные частицы, после 5 мин измельчения имело вид более развитой хаотичной структуры со средним масштабом шероховатости вдвое выше.
Сравнение РЭМ-изображений поверхности мембран CM Pes (рис. 1) показало, что после нагревания в воде при температуре $100{ }^{\circ} \mathrm{C}$ количество ионообменных частиц на поверхности уменьшается более, чем вдвое. Деструкция ионообменной составляющей мембран с меньшей степенью дисперсности в процессе термообработки сопровождается снижением доли проводящей поверхности на $47 \%$. При этом распределение участков выхода ионообменных частиц по размерам на поверхности мембран с ионообменниками после 5 и 80 мин измельчения практически не изменяется и составляет 0.7-12.0 и 0.6-11.0 мкм соответственно (рис. 4). Значение средневзвешенного радиуса ионопроводящих участков $\bar{R}$ на поверхности мембран после температурного воздействия уменьшается в обоих случаях на $30 \%$.

Оценка порового состава на поверхности набухших образцов мембран после температурного воздействия свидетельствует об увеличении размеров макропор на 20-30\%, что может являться результатом удаления частиц ионообменника из фазы мембраны, а также гидролитического окисления полиэтилена [23]. Длительное нагревание мембран приводит к росту поверхностной пористости и доли дефектов структуры более чем в 2.5 раза. Увеличение размеров и доли макропор (зазоров) меж- 

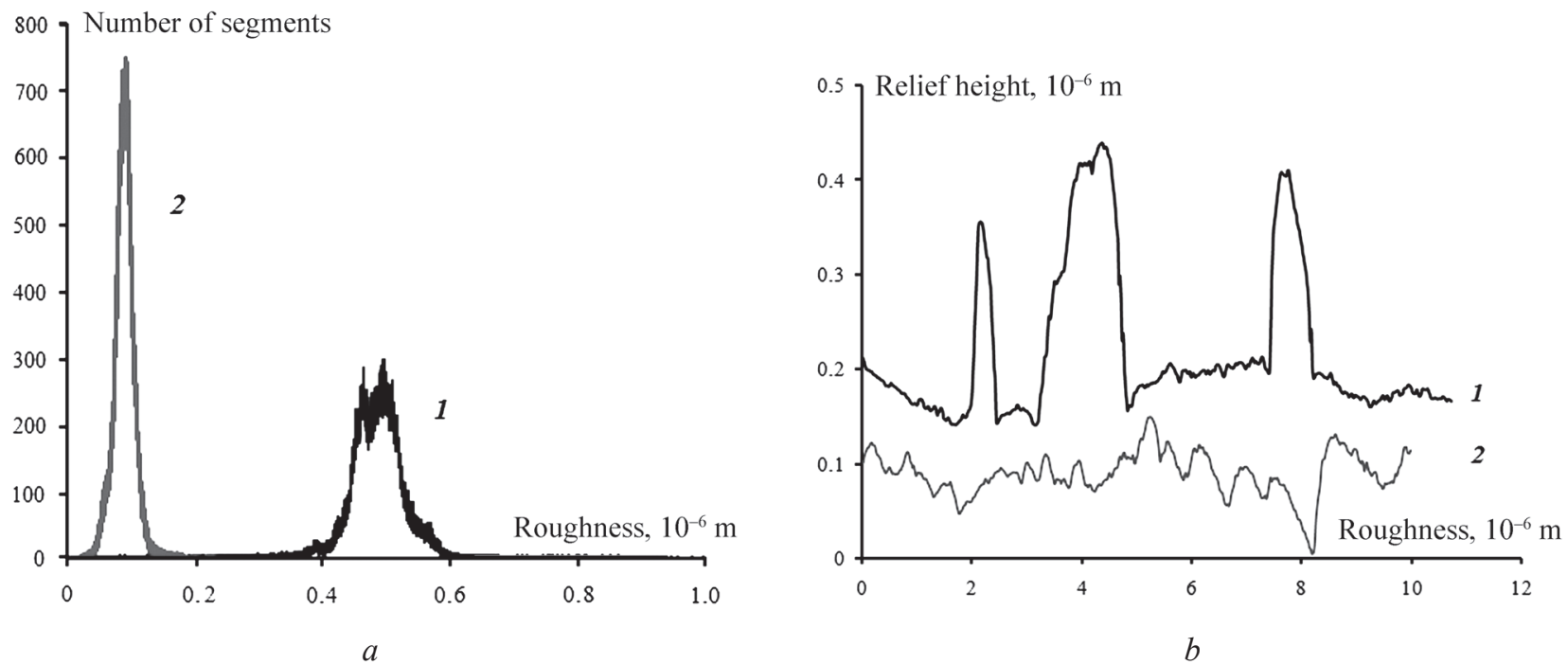

Рис. 3. Гистограмма плотности распределения значений высот для всего изображения образцов $(a)$ и микропрофили (b) мембран СM Реs со временем измельчения ионообменника 5 (1) и 80 (2) мин. Площадь сканирования $10 \times 10$ мкм

[Fig. 3. Histogram of the density distribution of the heights for the entire image of the samples $(a)$ and the microprofiles $(b)$ of the CM Pes membranes with the ion exchanger milling time of 5 (1) and 80 (2) min. Scanning area of $10 \times 10 \mu \mathrm{m}]$

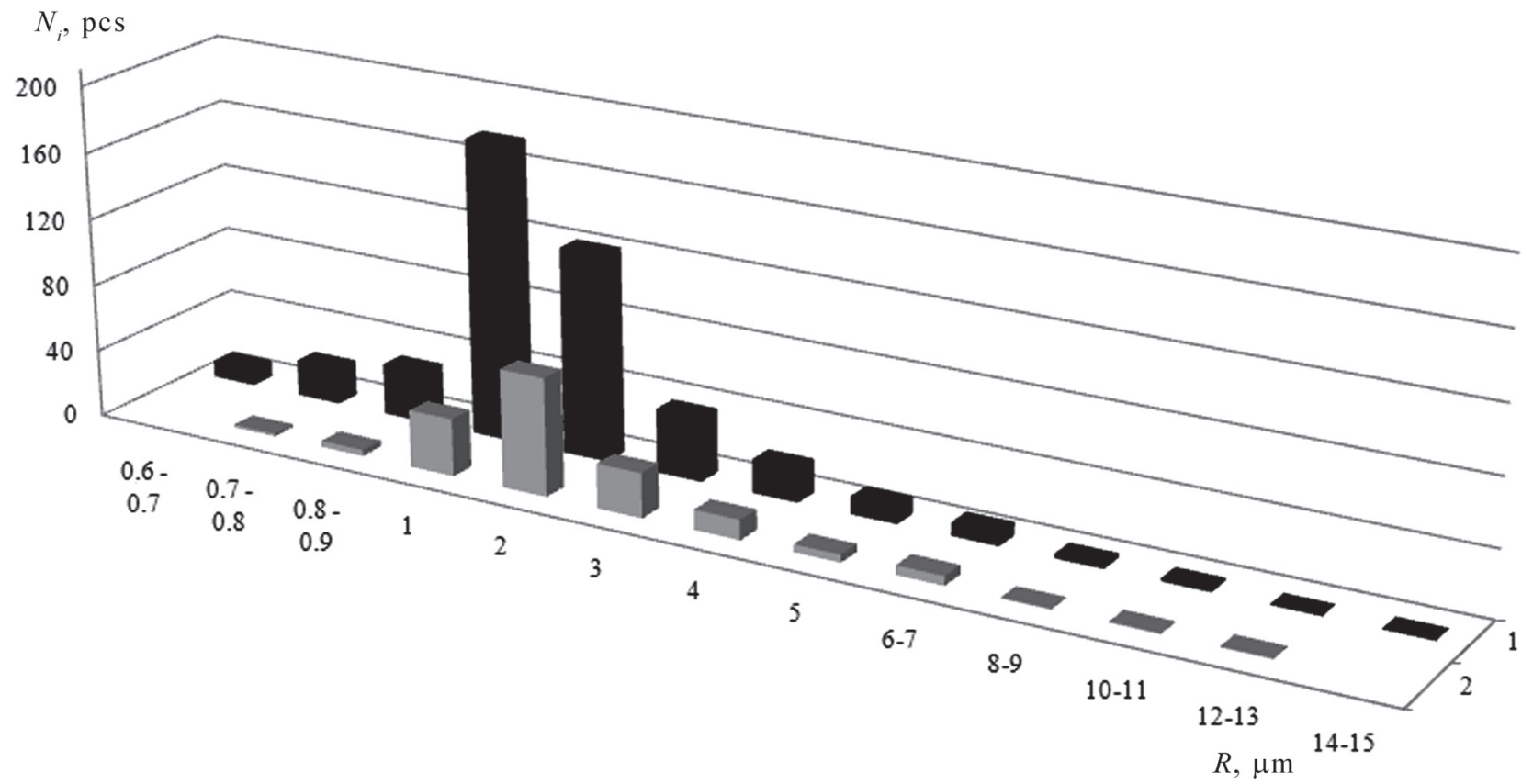

Рис. 4. Распределение участков ионообменника по радиусам на поверхности набухших образцов гетерогенных мембран CM Pes c ионообменниками после 5 мин измельчения после кондиционирования (1) и воздействия в воде при $100^{\circ} \mathrm{C}$ в течение 50 ч (2)

[Fig. 4. Distribution of the ion exchange areas over radii on the surface of the swollen samples of CM Pes ion exchange membranes with an ion exchanger milling time of 5 min after conditioning (1) and heating in water at $100{ }^{\circ} \mathrm{C}$ for $50 \mathrm{~h}(2)]$ 
ду частицами ионообменника и инертным связующим гетерогенных ионообменных мембран МК-40 и МА-41 после нагревания в воде было установлено в работах [24-26].

\section{ЗАКЛЮЧЕНИЕ}

Методами РЭМ и АСМ визуализированы различия в микроструктуре поверхности набухших экспериментальных образцов сульфокатионообменных мембран Ralex CM Pes с разным временем измельчения ионообменника. С увеличением степени дисперсности ионообменника выявлено сближение зон неоднородности, уменьшение линейных размеров ионообменных частиц и пор, менее развитый микрорельеф поверхности. Сравнительным анализом структурных свойств поверхности мембран показано, что в результате длительного воздействия повышенных температур происходит значительное увеличение макропористости и появление дефектов структуры, уменьшение доли ионообменной фазы. Установленные изменения микроструктуры мембран связаны с частичной деструкцией ионопроводящих и инертных полимеров.

Микрофотографии поверхности мембран получены в ЦКПНО ВГУ.

Работа выполнена при финансовой поддержке грантов РФФИ (проекты №№ 15-08-05031 и 16-38-00572 мол_а).

\section{СПИСОК ЛИТЕРАТУРЫ}

1. Rubinstein I., Maletzki F. // J. Chem. Soc., Faraday Trans. II, 1991, vol. 87, № 13, pp. 2079-2087.

2. Заболоцкий В. И., Лебедев К. А., Уртенов М. Х., Никоненко В. В., Василенко П. А., Шапошник В. А., Васильева В. И. // Электрохимия, 2013, т. 49, № 4, c. $416-427$.

3. Письменская Н. Д., Никоненко В. В., Мельник Н. А., Пурсели Ж., Ларше К. // Электрохимия, 2012, т. 48, № 6, с. 677-697.

4. Жильцова А. В., Васильева В. И., Малыхин М. Д., Письменская Н. Д., Мельник Н. А. // Вестник ВГУ, Серия: Химия, Биология, Фармащия, 2013, № 2, с. 3538.

5. Urtenov M. K., Uzdenova A. M., Kovalenko A. V., Nikonenko V. V., Pismenskaya N. D., Vasil'eva V. I., Sistat P., Pourcelly G. // J. Memb. Sci., 2013, vol. 447, pp. 190-202.

6. Васильева В. И., Жильцова А. В., Акберова Э. М., Фатаева А. И. // Конденсированные среды и межфазные гранищь, 2014, т. 16, № 3, с. 257-261.

7. Васильева В. И., Шапошник В. А., Заболоцкий В. И., Лебедев К. А., Петруня И. П. // Сорбционные и хроматографические проиессы, 2005, т. 5, № 4, c. $545-560$.

8. Vasil'eva V. I., Shaposhnik V. A., Grigorchuk O. V., Petrunya I. P. // Desalination, 2006, vol. 192, № 1-3, pp. 408-414.

9. Васильева В. И., Жильцова А. В., Малыхин М. Д., Заболоцкий В. И., Лебедев К. А., Чермит Р. Х., Шарафан М. В. // Электрохимия, 2014, т. 50, № 2, с. 134143.

10. Княгиничева Е. В., Белашова Е. Д., Сарапулова В. В., Письменская Н. Д. // Конденсированные среды и межфазные границы, 2014, т. 16, № 3, с. 282-287.

11. Акберова Э. М., Васильева В. И., Малыхин М. Д. // Конденсированные среды и межфазные гранииы, 2015, т. 17, № 3, с. 273-280.

12. Volodina E., Pismenskaya N., Nikonenko V., Larchet C., Pourcelly G. // J. Colloid Interface Sci., 2005, vol. 285 , pp. 247-258.

13. Nikonenko V. V., Pismenskaya N. D., Belova E. I., Sistat Ph., Huguet P., Pourcelly G., Larchet Ch. // Adv. Colloid Interface Sci., 2010, vol. 160, iss. 1-2, pp. 101-123.

14. Rubinstein I., Zaltzman B. // Phys. Rev. E, 2000, vol. 62 , pp. 2238-2251.

15. Zaltzman B., Rubinstein I. // J. Fluid. Mech. 2007, vol. 579, pp. 173-226.

16. Mishchuk N. A. // Adv. Colloid Interface Sci., 2010, vol. 160. № 1-2. pp. 16.

17. Сайт «MEGA a.s.» https://www.mega.cz/ (дата обращения 24.03.2017)

18. Васильева В. И., Акберова Э. М., Жильцова А. В., Черных Е. И., Сирота Е. А., Агапов Б. Л. // Поверхность. Рентгеновские, синхротронные и нейтронные исследования, 2013, № 9, с. 27-34.

19. Васильева В. И., Письменская Н. Д., Акберова Э. М., Небавская К. А. // Журн. физ. химии, 2014, т. 88, № 8, c. 1114-1120.

20. Сирота Е. А., Кранина Н. А., Васильева В. И., Малыхин М. Д., Селеменев В. Ф. // Вестник ВГУ, Серия: Химия. Биология. Фармачия, 2011, № 2, с. 53-59.

21. Глинка Н.Л. Общая химия. Ленинград, Химия, Ленинградское отд., 1987, 702 с.

22. Васильева В. И., Кранина Н. А., Малыхин М. Д., Акберова Э.М., Жильцова А. В. // Поверхность. Рентгеновские, синхротронные и нейтронные исследования, 2013, № 2, c. 51-61.

23. Henry J. L., Garton A. // J. of Polymer Science: Part A: Polymer Chemistry, 1990, vol. 28, pp. 945-948.

24. Dammak L., Larchet C., Grande D. // Separation and Purification Technology. 2009, vol. 69, № 1, pp. 4347.

25. Акберова Э. М., Малыхин М. Д. // Сорбиионные и хроматографические прочессы, 2014, т. 14, вып. 2, c. $232-239$.

26. Васильева В. И., Акберова Э. М., Заболоцкий В. И. // Электрохимия, 2017, т. 53, № 4, с. 452465. 


\title{
MICROSCOPIC ANALYSIS OF THE SURFACE OF HETEROGENEOUS MEMBRANES WITH A DIFFERENT DEGREE OF ION EXCHANGER DISPERSITY AFTER TEMPERATURE INFLUENCE
}

\author{
(C) 2017 E. M. Akberova, E. Yu. Kozhukhova, A. M. Yatsev, V. I. Vasil'eva \\ Voronezh State University, 1 Universitetskaya sq., 394018 Voronezh, Russia \\ e-mail: elmara_09@inbox.ru
}

Received 30.03.2017

\begin{abstract}
At present, one of the areas for the improvement of electromembrane methods of substance separation and isolation is the development of new membranes with optimized surface morphology that in particular can be achieved by the influence of elevated temperatures on ion-exchange materials. The purpose of this work is to evaluate the effect of temperature influence on the surface properties of experimental samples of heterogeneous sulfocation exchange membranes.

Experimental samples of heterogeneous cation-exchange membranes with varying dispersion degrees were chosen as the objects for investigation. The dispersion degree of sulfocation exchanger was varied by the use of different duration of its milling. The experimental studies of surface morphology of membranes were conducted using the scanning electron microscopy (SEM) and atomic force microscopy (AFM) methods. Microphase fractions and sizes were estimated by means of an original software system.

The differences in the microstructure of the experimental samples of the sulfocation exchange membranes with different ion exchanger milling time were visualized by SEM and AFM methods. From the analysis of micrographs of membrane samples, it was found that the proportion of ion exchanger for heterogeneous membranes CM Pes is $15-17 \%$. The increase in the duration of the milling of ion-exchange particles is accompanied by a change in their dispersion degree. With an increase in the dispersion degree of the ion exchanger, the decrease in the distances between inhomogeneity zones, in the linear dimensions of the ion-exchange particles and pores, and the less developed surface microrelief were revealed. A comparative analysis of the structural properties of the membrane surface showed that as a result of prolonged effect of elevated temperatures, a significant increase in macroporosity and the appearance of structural defects and a decrease in the fraction of the ion exchange phase occur. The established changes in the microstructure of sulfocation exchange membranes are due to the partial destruction of ion-conducting and inert polymers.
\end{abstract}

Keywords: heterogeneous sulfocation exchange membrane, surface heterogeneity, temperature influence.

\section{ACKNOWLEDGMENTS}

Microphotographs of the membranes surface were obtained with equipment of Voronezh State University Centre for Collective Use of Scientific Equipment

This work was financially supported by RFBR grants (projects Nos. 15-08-05031 and 16-38-00572 mol_a).

\section{REFERENCES}

1. Rubinstein I., Maletzki F. J. Chem. Soc., Faraday Trans. II, 1991, vol. 87, no. 13, pp. 2079-2087. DOI: 10.1039/FT9918702079

2. Zabolotskii V. I., Lebedev K. A., Urtenov M. Kh., Nikonenko V. V., Vasilenko P. A., Shaposhnik V. A., Vasil'eva V. I. Russ. J. Electrochem., 2014, vol. 49, no. 4, pp. 369-380. DOI: 10.1134/S1023193513040149
3. Pis'menskaya N. D., Nikonenko V. V., Mel'nik N. A., Pourcelli G., Larchet G. Russ. J. Electrochem., 2012, vol. 48, no. 6, pp. 610-628. DOI:10.1134/S1023193512060092

4. Zhil'tsova A. V., Vasil'eva V. I., Malykhin M. D., Pis'menskaya N. D., Mel'nik N. A. Proceedings of Voronezh State University. Series:Chemistry. Biology. Pharmacy, 2013, no. 2, pp. 35-38. Available at: http://www. vestnik.vsu.ru/program/view/view.asp?sec=chembio\&year $=2013 \&$ num $=02 \& f$ name $=2013-02-06$ (in Russian)

5. Urtenov M. K., Uzdenova A. M., Kovalenko A. V., Nikonenko V. V., Pismenskaya N. D., Vasil'eva V. I., Sistat P., Pourcelly G. J. Memb. Sci., 2013, vol. 447, pp. 190202. DOI: $10.1016 /$ j.memsci.2013.07.033

6. Vasil'eva V. I., Zhil'tsova A. V., Akberova E. M., Fataeva A. I. Condensed Matter and Interphases, 2014, vol. 16, no. 3, pp. 257-261. Available at: http://www.kcmf. vsu.ru/resources/t_16_3_2014_003.pdf (in Russian) 
7. Vasil'eva V. I., Shaposhnik V. A., Zabolotskiy V. I., Lebedev K. A., Petrunya I. P. Sorption and Chromatographic Processes, 2005, vol. 5, no. 4, pp. 545-560. (in Russian)

8. Vasil'eva V. I., Shaposhnik V. A., Grigorchuk O. V., Petrunya I. P. Desalination, 2006, vol. 192, no. 1-3, pp. 408-414. DOI:10.1016/j.desal.2005.06.055

9. Vasil'eva V. I., Zhil’tsova A. V., Malykhin M. D., Zabolotskii V. I., Lebedev K. A., Chermit R.Kh., Sharafan M. V. Russ. J. Electrochem., 2014, vol. 50, no. 2, pp. 120-128. DOI:10.1134/S1023193514020062

10. Kniaginicheva E. V., Belashova E. D., Sarapulova V. V., Pismenskaya N. D. Condensed Matter and Interphases, 2014, vol. 16, no. 3, pp. 282-287. Available at: www. kcmf.vsu.ru/resources/t_16_3 2014_007.pdf (in Russian)

11. Akberova E. M., Vasil'eva V. I., Malykhin M. D. Condensed Matter and Interphases, 2015, vol. 17, no. 3, pp. 273-280. Available at: http://www.kcmf.vsu.ru/article. php?l=ru\&aid $=686$ (in Russian)

12. Volodina E., Pismenskaya N., Nikonenko V., Larchet C., Pourcelly G. J. Colloid Interface Sci., 2005, vol. 285, pp. 247-258. DOI:10.1016/j.jcis.2004.11.017

13. Nikonenko V. V., Pismenskaya N. D., Belova E. I., Sistat Ph., Huguet P., Pourcelly G., Larchet Ch. Adv. Colloid Interface Sci., 2010, vol. 160, iss. 1-2, pp. 101-123. DOI: 10.1016/j.cis.2010.08.001

14. Rubinstein I., Zaltzman B. Phys. Rev. E, 2000, vol. 62, pp. 2238-2251. DOI: 10.1103/PhysRevE.62.2238

15. Zaltzman B., Rubinstein I. J. Fluid. Mech. 2007, vol. 579, pp. 173-226. DOI: 10.1017/S0022112007004880

16. Mishchuk N.A. Adv. Colloid Interface Sci., 2010, vol. 160. № 1-2. pp. 16. DOI: 10.1016/j.cis.2010.07.001

17. «MEGA a.s.» https://www.mega.cz/ (accessed 24.03.2017)
18. Vasil'eva V. I., Akberova E. M., Zhiltsova A. V., Chernykh E. I., Sirota E. A., Agapov B. L. J. Surface Investigation. Xray, Synchrotron and Neutron Techniques, 2013, vol. 7, no. 5, pp. 833-840. DOI:10.1134/S102745101 3050194

19. Vasil'eva V. I., Pismenskaya N. D., Akberova E. M., Nebavskaya K. A. Russ. J. Phys. Chem. A, 2014, vol. 88, no. 8, pp. 1293-1299. DOI:10.1134/S0036024414080317

20. Sirota E. A., Kranina N. A., Vasil'eva V. I., Malykhin M. D., Selemenev V. F. Proceedings of Voronezh State University. Series: Chemistry. Biology. Pharmacy, 2011, no. 2, pp. 53-59. Available at: http://www.vestnik.vsu.ru/ program/view/view.asp? $\mathrm{sec}=$ chembio $\&$ year $=2011 \&$ num $=$ 02\&f_name $=2011-02-08$ (in Russian)

21. Glinka N. L. General Chemistry. Leningrad, Chemistry Publ., Leningrad Department, 1987, 702 p. (in Russian)

22. Vasil'eva V. I., Kranina N. A., Malykhin M. D., Akberova E. M., Zhiltsova A. V. J. Surface Investigation. Xray, Synchrotron and Neutron Techniques, 2013, vol. 7, no. 1, pp. 144-153. DOI:10.1134/S1027451013010321

23. Henry J. L., Garton A. // J. of Polymer Science: Part A: Polymer Chemistry, 1990, vol. 28, pp. 945-948. DOI:10.1002/pola.1990.080280420

24. Dammak L., Larchet C., Grande D. // Separation and Purification Technology. 2009, vol. 69, no. 1, pp. 43-47. DOI:10.1016/j.seppur.2009.06.016

25. Akberova E. M., Malykhin M. D. Sorption and Chromatographic Processes, 2014, vol. 14, no. 2, pp. 232239. Available at: http://www.sorpchrom.vsu.ru/articles/20140207.pdf (in Russian)

26. Vasil'eva V. I., Akberova E. M., Zabolotskii V. I. Russ. J. Electrochem., 2017, vol. 53, no. 4, pp. 398-410.
Акберова Эльмара Маликовна - к. х. н., ведущий инженер кафедры аналитической химии; Воронежский государственный университет; e-mail: elmara_09@inbox.ru

Яиеев Андрей Михайлович - магистрант химического факультета, Воронежский государственный университет

Кожухова Евгения Юрьевна - магистрант химического факультета, Воронежский государственный университет

Васильева Вера Ивановна - д. х. н., профессор кафедры аналитической химии, Воронежский государственный университет; e-mail: viv155@mail.ru
Akberova Elmara M. - Cand. Sci. (Chem.), Leading Engineer of the Analytical Chemistry Department, Voronezh State University; e-mail: elmara_09@inbox.ru

Yatsev Andrey M. - the competitor for science degree of Master Science in Chemistry of the Analytical Chemistry Department, Voronezh State University

Kozhukhova Evgeniya Yu. - the competitor for science degree of Master Science in Chemistry of the Analytical Chemistry Department, Voronezh State University

Vasil'eva Vera I. - Dr. Sci. (Chem.), Professor of the Analytical Chemistry Department, Voronezh State University; e-mail: viv155@mail.ru 